\title{
Effect of Iron, Zinc, Vitamin E and Vitamin C Supplementation on Thyroid Hormones in Rats with Hypothyroidism
}

\author{
Naeem M. Rabeh ${ }^{1}$, Hanan A. El-Ghandour ${ }^{2}$ \\ ${ }^{1}$ Food and Nutrition Dept., Home Economic Faculty, Helwan University, Cairo, Egypt \\ ${ }^{2}$ Agriculture Research Center, Regional Center for Food and Feed, Giza, Egypt \\ Email address: \\ naeemrabeh@gmail.com (N. M. Rabeh), hananelghandour@yahoo.com (H. A. El-Ghandour)
}

\section{To cite this article:}

Naeem M. Rabeh, Hanan A. El-Ghandour. Effect of Iron, Zinc, Vitamin E and Vitamin C Supplementation on Thyroid Hormones in Rats with Hypothyroidism. International Journal of Nutrition and Food Sciences. Vol. 5, No. 3, 2016, pp. 201-210.

doi: $10.11648 /$ j.ijnfs.20160503.18

Received: April 1, 2016; Accepted: April 11, 2016; Published: May 10, 2016

\begin{abstract}
The aim of the study was to investigate the effect of Iron, Zinc, Vitamin C (Vit.C) and Vitamin E (Vit.E) supplementation on thyroid hormones in rats with hypothyroidism. Thirty six rats were divided into two main groups, the first main group (6 rats) was fed on basal diet only. The second main group (30 rat) were injected with $10 \mathrm{mg} / \mathrm{kg} / \mathrm{day}$ Propylthiouracil (PTU) to induce hypothyroidism, was divided into 5 subgroups: including control positive group that fed on basal diet, and the other subgroups were fed on basal diet supplemented with $40 \mathrm{mg}$ ferric sulphate $/ \mathrm{kg}$ diet, $200 \mathrm{mg}$ zinc carbonate $/ \mathrm{kg}$ diet, $250 \mathrm{mg} \alpha$ - tocohperol acetate $/ \mathrm{kg} / \mathrm{B}$.W. and $250 \mathrm{mg}$ ascorbic acid $/ \mathrm{kg} / \mathrm{B}$.W. respectively. Blood samples were collected from each rat and were centrifuged to obtain serum. PTU exposed rats showed hypothyroidism with significant $(\mathrm{P}<0.05)$ decline in serum FT3 and FT4 levels together with significant $(\mathrm{P}<0.05)$ increase in serum TSH level. The supplementation with Iron, Zinc, Vit.E or Vit.C significantly $(\mathrm{P}<0.05)$ increased the level of thyroid hormones (FT4 and FT3) and glutathione peroxidase, moreover, the level of TSH was significantly $(\mathrm{P}<0.05)$ decreased, compared with control positive group, might be due to their antioxidant properties. Significant improvement in lipid profile as well as liver and kidney functions were observed. It could be suggested that Vitamin C, Vitamin E, Zinc and Iron could be used as a suitable supplementation therapy for hypothyroidism patients.
\end{abstract}

Keywords: Hypothyroidism, Iron, Zinc, Vitamin E, Vitamin C, Thyroid Functions, Lipid Profile, Rats, Propylthiouracil

\section{Introduction}

Hypothyroidism is a clinical entity resulting from deficiency of thyroid hormones or, more rarely, from their impaired activity at the tissue level. In hypothyroidism, the basal metabolic rate is decreased, as are other processes dependent upon thyroid hormones [1].Thyroid hormones are secreted by follicular cells in the thyroid gland. A thyroidstimulating hormone (TSH) stimulates the secretion of thyroid hormones, including triiodothyronine (T3) and thyroxin (T4). Thyroxine is converted to T3 by (5'deiodinase) in other tissues, including the kidney $[2,3]$.

Thyroid diseases are primarily conditions that affect the amount of thyroid hormones being produced. Excess production of thyroid hormones leads to hyperthyroidism while diminished production leads to hypothyroidism [4]. Thyroid disease, constitutes the most common endocrine abnormality in recent years, diagnosed either in subclinical or clinical form and is associated with various metabolic abnormalities, due to the effects of thyroid hormones on nearly all major metabolic pathways [5], increasing the basal metabolic rate, affecting protein synthesis, regulating the metabolism of protein, lipids and carbohydrates [6] and involved in the regulation of oxidative metabolism [7]. They can cause many changes in the number and activity of mitochondrial respiratory chain components. This may result in the increased generation of reactive oxygen species (ROS) $[8,9]$. Some studies have shown an increased production of 
ROS in hypothyroidism [10, 11].

Hypothyroidism is commonly treated with iodine supplements or thyroid hormone replacements. However, there are other natural supplements that can support thyroid functioning either by protecting the thyroid gland from injury or by increasing the production of thyroid hormones.

In fact, the cell contains a variety of substances capable of scavenging the free radicals, protecting them from harmful effects. Among the enzymatic antioxidants, are glutathione reductase, glutathione peroxidase, catalase, superoxide dismutase, while the non-enzymatic antioxidants are glutathione, Vit.E, Vit.C, $\beta$-carotene and flavonoids [12-15].

Vitamin $\mathrm{E}$ is a potent lipid soluble antioxidant in biological systems with the ability to directly quench free radicals and function as membrane stabilizer [16]. It is well known that Vitamin $\mathrm{E}$ acts as an antioxidant within cells and the mechanisms which contribute to its efficacy involve the suppression of free radicals and improvement in antioxidant system status [17]. Deshpande, et al. (2002) [18] found that the rats received Vit.C and Vit.E along with methimazole induced hypothyroidism showed statistically significant reduced weight $(38-55 \%$ less $)$ of the thyroid glands $(\mathrm{P}<0.01)$.The positive effect of antioxidants on thyroid gland could be due to direct involvement of antioxidants on thyroid gland.

Trace minerals have been shown to influence hormones at several levels, including hormone secretion and activity and binding to the target tissue [19]. Moreover, several minerals are essential for normal thyroid hormone metabolism, e.g., Iodine, Iron, Zinc and Selenium. Coexisting deficiencies of these elements can impair thyroid function. Iron deficiency impairs thyroid hormone synthesis by reducing activity of heme-dependent thyroid peroxidase. Iron-deficiency anemia blunts and Iron supplementation improves the efficacy of Iodine supplementation [20]. Zinc is a known fundamental component of the endogenous enzymatic antioxidant system and plays an essential role in cell membrane integrity and functions in many aspects of cellular metabolism [21, 22]. Zinc is also required for the activity of the enzyme 1,5'deiodinase, which converts biologically T4 to T3 [23, 24]. The fact that Zinc levels are lower in hypothyroidism Baltaci, et al. (1999) [25] points out to a relationship between Zinc and thyroid gland. Hypothyroidism rats supplemented with PTU had lower Calcium, Selenium and Zinc levels and higher Chromium, Copper, Iron and Phosphorus levels relative to control group [26].

Thus, the present study was carried out to investigate the possible role of vitamins (Vit.C and Vit.E) and minerals (Iron and Zinc), supplementation on thyroid hormones in experimental hypothyroidism-induced by PTU.

\section{Materials and Methods}

\subsection{Materials}

Casein, vitamins, minerals, cellulose, choline chloride, ferric sulphate, zinc carbonate, L. Ascorbic Acid (Vit.C) and $\alpha$-tocopherol acetate (Vit.E) were purchased from ElGomhoria Company, Cairo, Egypt. Propylthiouracil was obtained from Sigma Chemical Co., USA. Kits for blood analysis were purchased from local distributer (Sigma chemical) Cairo, Egypt.

Animals:

Thirty six adult male albino rats (Sprague- Dawley strain) at the age of 8 weeks $(200 \pm 5$ g.) were purchased from Helwan Experimental Animals Station. The study was carried out at the Animal House of Agriculture Research Center, Giza, Egypt. Rats were housed in well aerated cages under hygienic conditions, kept at a constant temperature $\left(22 \pm 1^{\circ} \mathrm{C}\right)$ under $12 \mathrm{~h}$ light: $12 \mathrm{~h}$ darkness cycles and fed on basal diet for one week for adaptation.

\subsection{Methods}

\subsubsection{Induction of Hypothyroidism}

Propylthiouracil (6-n-propyl-2- thiouracil) was dissolved in $0.1 \mathrm{NaOH} / 0.9 \% \mathrm{NaCl}$ and administered as $10 \mathrm{mg} / \mathrm{kg}$. B.W./day $(1 \mathrm{ml} / 250 \mathrm{~g})$ by i.p. injection for 15 day according to Sener et al. (2006) [27]. Blood was collected and the serum was separated to measure $\mathrm{T} 3, \mathrm{~T} 4$ and $\mathrm{TSH}$.

\subsubsection{Biological Study}

The basal diet was formulated according to Reeves, et al. (1993) [28]. After adaptation period, rats were divided into two main groups as follows:- the first main group (6 rats) was fed on basal diet (as a control negative group). The second main group (30 rat with hypothyroidism) was divided into 5 sub groups (6 rats each): subgroup (1) was fed on basal diet (as a control positive group), subgroup (2) was fed on basal diet and supplemented with (40 mg ferric sulphate/kg diet), subgroup (3) was fed on basal diet and supplemented with (200 mg zinc carbonate/kg diet), subgroup (4) was fed on basal diet and supplemented with (250 $\mathrm{mg} \alpha$ - tocohperol acetate $/ \mathrm{kg} / \mathrm{B}$.W.) and subgroup (5) was fed on basal diet and supplemented with (250 mg ascorbic acid $/ \mathrm{kg} / \mathrm{B}$.W.).

At the end of the experimental period ( 8 weeks), rats were fasted overnight before sacrificing, dissected under slight anesthesia by ether and the blood samples were collected from each rat and were centrifuged to obtain serum which was stored at $-20^{\circ} \mathrm{C}$ until chemical analysis.

\subsubsection{Biochemical Analysis}

Free triiodothyronine (FT3), free thyroxin (FT4) and TSH hormones were measured in serum using radioimmunoassay method provided by Ortho-Clinical Diagnostics, Inc, USA according to manufacturer's instruction Agharanya (1990); Frank et al. (1996); Sachidhanandam et al. 2010) [29-31] and Glutathione peroxidase (GPx) concentration was determined according to Beutler et al. (1963) [32]. Serum concentration of total cholesterol (TC), triglycerides (TG) and high density lipoprotein cholesterol (HDL-C) were estimated enzymatically according to Richmond, (1973) [33]; Wahlefeld, (1974) [34] and Albers et al. (1983) [35], respectively, meanwhile low density lipoprotein cholesterol (LDL-C) and very low density lipoprotein cholesterol 
(VLDL-C) were calculated according to the equation of Freidewald et al. (1972) [36]. AST and ALT activities were determined according to method of Reitman and Frankel (1957) [37]. Serum ALP was estimated by method of Belfield and Goldberg (1971) [38]. Creatinine level was determined by the method of Tietz (1999) [39]. Urea level was determined by using the method of Wills and Savory (1981) [40].

\subsubsection{Statistical Analysis}

The results were presented as mean \pm SE. The obtained data were analyzed according to SPSS program, through the use of the analysis of variance (ANOVA) and the differences among groups were determined by Duncan's multiple range tests as post test. The results were considered statistically significant at $(\mathrm{P}<0.05)$ [41].

\section{Results and Discussion}

The present work was designed to evaluate the possible protective effect of Iron, Zinc, Vit.E and Vit.C supplementation on thyroid hormones, lipid profile furthermore liver and kidney functions in experimentally induced hypothyroidism of adult male albino rats.

Results in Table (1) demonstrated the effect of Iron, Zinc, Vit.E and Vit.C supplementation on thyroid hormones. In the present study, PTU exposed rats showed hypothyroidism which was evidenced biochemically by significant $(\mathrm{P}<0.05)$ decrease in serum T3 and T4 levels with significant $(\mathrm{P}<0.05)$ increase in serum TSH level as compared to control rats. These results are in agreement with Sener et al. (2006) [27] who reported that PTU dramatically reduced thyroid hormones. Serum concentrations of thyroid hormones (T3, T4) and TSH are commonly used as reliable indicators of the thyroid function in humans and experimental animals [42]. PTU effects may be due to inhibiting the thyroid hormone synthesis and blocking the transformation of T4 to T3 [43]. The prohormone T4 is then converted to its biologically active form T3 by iodothyronine deiodinase, which is present in highest amounts in liver, kidney, thyroid and pituitary [44]. Deiodinase is strongly inhibited by the anti-thyroid drug PTU [45].

Table 1. Effect of Iron, Zinc, Vitamin E and Vitamin C supplementation on thyroid hormones concentration in rats suffer from hypothyroidism.

\begin{tabular}{llll}
\hline Groups & PTarameters $(\mathbf{n g} / \mathbf{d L})$ & FT3 $(\mathbf{p g} / \mathbf{m L})$ & TSH $(\mu \mathbf{I U} / \mathbf{m L})$ \\
\hline Control - ve & $1.38 \pm 0.084^{\mathrm{a}}$ & $6.04 \pm 0.15^{\mathrm{a}}$ & $1.79 \pm 0.22^{\mathrm{e}}$ \\
Control + ve & $0.396 \pm 0.020^{\mathrm{f}}$ & $3.63 \pm 0.18^{\mathrm{e}}$ & $6.74 \pm 0.23^{\mathrm{a}}$ \\
Iron & $0.526 \pm 0.032^{\mathrm{e}}$ & $4.19 \pm 0.09^{\mathrm{d}}$ & $4.92 \pm 0.09^{\mathrm{b}}$ \\
Zinc & $0.835 \pm 0.021^{\mathrm{c}}$ & $4.87 \pm 0.07^{\mathrm{c}}$ & $3.30 \pm 0.46^{\mathrm{cd}}$ \\
Vitamin E & $0.676 \pm 0.024^{\mathrm{d}}$ & $4.77 \pm 0.10^{\mathrm{c}}$ & $4.06 \pm 0.20^{\mathrm{c}}$ \\
Vitamin C & $0.966 \pm 0.014^{\mathrm{b}}$ & $5.52 \pm 0.19^{\mathrm{b}}$ & $2.72 \pm 0.28^{\mathrm{d}}$ \\
\hline
\end{tabular}

$*$ Values were expressed as Means $\pm \mathrm{SE}$.

* Values at the same column with different letters are significant at $\mathrm{P}<0.05$
The supplementation with Iron, Zinc, Vit.E and Vit.C significantly $(\mathrm{P}<0.05)$ increased the concentration of thyroid hormones FT4 and FT3 and also caused a significant $(\mathrm{P}<0.05)$ decrease in the mean value of TSH, compared with control positive group.There are several trace elements that are needed for the normal function, synthesis and metabolism of the thyroid gland. Zinc has an important place among these elements [46]. Zinc deficiency reduce the activity of 5deiodinase in liver fell by $67 \%$, so that Zinc deficiency caused a reduction in conversion of $\mathrm{T} 4$ to $\mathrm{T} 3$ and in return $\mathrm{T} 3$ requires Zinc to fulfill its biological activity [47]. Similar results were found by Nishiyama et al. (1994) [24] who mentioned that Zinc plays a role in thyroid hormone metabolism and in the conversion of T4 to T3. Zinc-induced reduction in thyroid hormones could be due to its effects on deiodinase activity through its antioxidant properties [48]. Moreover, Zinc status and serum thyroid hormone levels were improved in goitrous patients after six months treatment with Zinc supplementation [49]. On the other hand, suppression of T3 and T3/T4 was found in a study in which rats were supplemented with Zinc chloride, due to a reduction in microsomal capacity to convert T4 to T3 [50]. Our results are not consistent with these reports. In the present study, Zinc generally led to an increase in thyroid hormone levels. The discrepancy may be explained by differences in the manner, duration and type of Zinc administration.

The current results are in agreement with Beard et al. (1990) [51] who found that T3 and T4 levels were significantly lower, TSH levels were significantly higher in anemic patients and they have demonstrated that T3 levels have been increased with Iron therapy. The two initial steps of thyroid hormone synthesis are catalyzed by thyroperoxidases (heme-containing thyroid peroxidase) and are dependent on Iron [52]. Severe Iron deficiency may lower thyroid peroxidase activity and interfere with the synthesis of thyroid hormones $[53,54]$. The same results were illustrated by Gökdeniz et al. (2010) [55] who reported that hormonal changes returned to normal values with Iron supplementation. Also, Soliman et al. (2010) [56] found that total T3 (tT3) and total T4 (tT4) levels of anemic rats were significantly lower than normal control and tT3/tT4 ratio was significantly higher in group treated with $(40 \mathrm{mg}$ ferrous sulphate $/ \mathrm{kg}$ diet) than normal control group.

In the current work, it was clear that, Vit.C caused the highest increase the mean value of FT4 and FT3 and lowest decreases in the mean value of TSH followed by Zinc then Vit.E and finally Iron supplementation. The marginal decrease in serum $\mathrm{T} 3$ and $\mathrm{T} 4$ and the significant $(\mathrm{P}<0.05)$ increase in the concentrations of TSH and malonaldehyde in the group coadministered with Chlorpyrifos and Lead were ameliorated by Vit.C $(100 \mathrm{mg} / \mathrm{kg})$ partly due to its antioxidant properties [57]. The circulating levels of T3 were significantly $(\mathrm{P}<0.05)$ increased in Vit.C, Vit.E and Turmeric extract treated rats. The thyroid hormones responded to antioxidants indicating the significance of antioxidants for the prevention of certain diseases in thyroid gland by 
protecting biological system against potentially harmful effects of processes or reactions that can cause excessive oxidations [58].

Moreover, there were a significant $(\mathrm{P}<0.05)$ differences in FT3, FT4 and TSH among the groups fed on Iron, Zinc, Vit.E or Vit.C supplementation respectively. It was observed that, Vit.C was more effective in hypothyroidism rats than Vit.E in reducing the levels of TSH and increasing the levels of FT4 and FT3. The same manner was observed for Zinc when compared to Iron supplementation.

Data tabulated in Table (2) illustrated the effect of Iron, Zinc, Vit.E and Vit.C supplementation on glutathione peroxidase activity in rats suffer from hypothyroidism. There was a significant $(\mathrm{P}<0.05)$ decrease in the concentration of glutathione peroxidase as a result of PTU injection, compared with negative control group. The level of glutathione peroxidase was significantly $(\mathrm{P}<0.05)$ increased in all groups fed on Vitamins $\mathrm{E}$ or $\mathrm{C}$ and on Iron or Zinc supplementations, compared with positive control group. There was a significant difference in the level of glutathione peroxidase among the rats fed on different diets supplemented with Iron, Zinc, Vit.E or Vit.C. It was observed that, the highest increase in the level of glutathione peroxidase was found in the group fed basal diet supplemented with Vit.C followed by Zinc, Vit.E then Iron. Therefore, supplementation with antioxidants Vit.E, Vit.C, Zinc and Iron was able to support the activities of antioxidant enzymes during hypothyrodism leading to delay the development of oxidative disease.

Table 2. Effect of Iron, Zinc, Vitamin E and Vitamin C supplementation on glutathione peroxidase in rats suffer from hypothyroidism.

\begin{tabular}{lll}
\hline Groups & Parameters & (GPx)mmol/min /ml \\
\hline Control - ve & $3.65 \pm 0.29^{\mathrm{a}}$ \\
Control + ve & $0.43 \pm 0.05^{\mathrm{d}}$ \\
Iron & $1.70 \pm 0.08^{\mathrm{c}}$ \\
Zinc & $2.77 \pm 0.14^{\mathrm{b}}$ \\
Vitamin E & $2.10 \pm 0.05^{\mathrm{c}}$ \\
Vitamin C & $3.38 \pm 0.19^{\mathrm{a}}$ \\
\hline
\end{tabular}

*Values were expressed as Means $\pm \mathrm{SE}$.

* Values at the same column with different letters are significant at $\mathrm{P}<0.05$

Lipid peroxidation, oxidative stress and the malfunction of respiratory chain in the mitochondria induced by hypothyroidism are the results of both increased production of free radicals and reduced capacity of antioxidative defense [59-61].

GPx are a family of selenium containing enzymes that responsible for detoxification of $\mathrm{H}_{2} \mathrm{O}_{2}$ and lipid peroxides at the membrane level into less reactive species using cellular GSH as substrate thus preventing the progressive formation of free radicals and provide the cell important protection against oxidative stress and LPO [62]. Many cells contain both CAT and GPx, while the brain GPx seems to be the major importance [63].
Vitamin C, a water soluble antioxidant is the most important free radical scavenger in extracellular fluids, trapping radicals in the aqueous phase and protects biomembranes from peroxidative damage [64]. Moreover, Vitamin E is a potent lipid soluble antioxidant in biological systems with the ability to directly quench free radicals and function as membrane stabilizer [16]. Antioxidants treatments might be helpful in reducing the oxidative damage due to hypothyroidism [65, 66]. Other experimental study Sarandol et al. (2005) [65] indicated that Vit.E supplementation significantly $(\mathrm{P}<0.05)$ increased liver and kidney reduced glutathione levels. A different result was obtained in the study conducted by Adali et al. (1999) [67] who found no beneficial effects of Vit.E supplementation on the antioxidant status in patients with hypothyroidism. It may be suggested that Copper and Zinc serve as antioxidant molecules and exert their effects in an indirect manner to reduce oxidative stress in experimental hypothyroidism [68].

The effect of Iron, Zinc, Vit.E and Vit.C supplementation on lipid profile in rats suffer from hypothyroidism was illustrated in Table (3). It was clear that, PTU produced hypercholesterolemia that remarkable significant $(\mathrm{P}<0.05)$ increase in TC, TG, VLDL-C and LDL-C levels, compared to the normal group, however, no significant changes was observed in the mean value of HDL-C for the group treated with PTU, compared with control negative group. The most common abnormalities of lipoprotein metabolism associated with hypothyroidism are elevated levels of TC and LDL-C, which are attributable to the effect of thyroid hormone on lipoprotein lipase activity [69].

The current results are in the line with Walsh et al. (2005) [70] who reported increased levels of TC and LDL-C in adults with subclinical hypothyroidism compared with euthyroid controls. In adults, increasing levels of TSH to be associated with increases in TC, LDL-C and TG and with decreases in HDL-C [71]. Moreover, Saleh (2015) [72] reported that, there was a significant $(\mathrm{P}<0.05)$ elevation in serum levels of lipid profile (TC, TG and LDL-C) in rats with hypothyroidism. Thyroid function regulates some metabolic parameters as lipoprotein metabolism (so any disturbance in thyroid hormones leads to dyslipidemia) and some cardiovascular disease risk factors [73, 74].

The results in table (3) indicated also that, there was a slight increase in the mean value of HDL-C among all treated groups, compared with control positive group. On the other hand, supplementation with Zinc, Vit.E and Vit.C significantly $(\mathrm{P}<0.05)$ decreased the mean value of lipid profile (TC, TG, VLDL-C and LDL-C), compared with control positive group. However, Iron supplementation didn't cause any significant changes in the level of lipid profile. It was obvious that, the lowest decrease in TG and VLDL-C was seen in the group treated with either Vitamin $\mathrm{E}$ or $\mathrm{C}$ followed by Zinc supplementation. Moreover, there was no significant changes were observed in the mean value of serum TC and LDL-C among the treated groups. Vitamin C supplementation was also able to cause reduction in LDL-C level to similar levels compared to normal group. 
Zinc supplementation (30 mg/d Zinc gluconate) improves body weight and TG concentration without considerable effects on lipid profile in 60 obese participants [75]. Hyperlipidemia may possibly be related to a decrease in the level of serum Zinc in hyperlipidemic adult men. The data also supports the concept that Zinc supplementation might be useful in improving metabolic complications in subjects with hyperlipidemia and this effect may be due to the role of Zinc as an antioxidant [76]. Zinc can act as an endogenous protective factor against atherosclerosis by inhibiting the oxidation of LDL-C and inhibiting the activation of oxidative stress [77]. Our findings are in agreement with previous studies which showed treatment with Zinc reduced TC, TG, and LDL-C plasma levels and increased HDL-C levels [78].

Severe Iron deficiency anemia in girls is attended by decreased concentrations of serum total cholesterol and triglyceride, and that these reduced serum lipid levels return to normal following Iron supplementation $(80 \mathrm{mg}$ of elemental Iron) per day for 3 months [79].

Administration of Vit.E in individuals with hyper or hypothyroidism reduced oxidative stress, decreased sensitivity to thyroid hormones, and prevented peroxidation of circulating LDL lipoproteins [80-10]. Rats treated with Vit.C, Vit.E and turmeric extract showed hypocholesterolaemic responses with respect to methimazole induced hypothyroidism treatment [18].

Table (4) illustrated the effect of Iron, Zinc, Vit.E and Vit.C supplementation on the levels of AST, ALT and ALP in rats suffers from hypothyroidism. Results revealed that the levels of AST, ALT and ALP increased significantly $(\mathrm{P}<0.05)$ in the control positive group, compared with the negative control group. Liver enzymes are one of the determining factors of the functional state of the organ and assessing the hepatotoxic potentials of exogenous compounds. Hence, liver dysfunction is characterized by alteration in serum levels of liver enzymes and metabolic products [81]. In this respect, a complex relationship exists between the thyroid gland and the liver in both health and disease. Thyroid hormones regulate the basal metabolic rate of all cells of the body including hepatocytes and thereby modulate liver function.

Table 3. Effect of Iron, Zinc, Vitamin E and Vitamin C supplementation on lipid profile in rats suffer from hypothyroidism.

\begin{tabular}{|c|c|c|c|c|c|}
\hline \multirow[b]{2}{*}{ Groups } & TC & TG & VLDL-C & HDL-C & LDL-C \\
\hline & \multicolumn{5}{|l|}{$(\mathrm{mg} / \mathrm{dl})$} \\
\hline Control - ve & $61.26 \pm 1.71^{\mathrm{c}}$ & $71.86 \pm 1.04^{\mathrm{d}}$ & $14.37 \pm 0.20^{\mathrm{d}}$ & $43.43 \pm 0.80^{\mathrm{a}}$ & $3.46 \pm 1.69^{c}$ \\
\hline Control + ve & $86.03 \pm 2.65^{\mathrm{a}}$ & $139.26 \pm 4.39^{\mathrm{a}}$ & $27.85 \pm 0.87^{\mathrm{a}}$ & $34.93 \pm 3.12^{\mathrm{a}}$ & $23.24 \pm 4.73^{\mathrm{a}}$ \\
\hline Iron & $82.31 \pm 1.45^{\mathrm{ab}}$ & $135.00 \pm 4.00^{\mathrm{ab}}$ & $27.00 \pm 0.80^{\mathrm{ab}}$ & $36.34 \pm 1.20^{\mathrm{a}}$ & $19.00 \pm 1.89^{\mathrm{ab}}$ \\
\hline Zinc & $73.46 \pm 3.64^{b}$ & $117.26 \pm 5.54^{\mathrm{b}}$ & $23.45 \pm 1.10^{\mathrm{b}}$ & $41.20 \pm 4.17^{\mathrm{a}}$ & $8.81 \pm 1.65^{\mathrm{bc}}$ \\
\hline Vitamin E & $69.80 \pm 3.18^{\mathrm{b}}$ & $97.0 \pm 1.15^{\mathrm{c}}$ & $19.40 \pm 0.23^{\mathrm{c}}$ & $42.66 \pm 4.33^{\mathrm{a}}$ & $7.73 \pm 1.04^{\mathrm{bc}}$ \\
\hline Vitamin C & $72.76 \pm 2.42^{\mathrm{b}}$ & $106.30 \pm 2.93^{c}$ & $21.26 \pm 0.58^{c}$ & $45.13 \pm 3.14^{\mathrm{a}}$ & $6.37 \pm 2.14^{\mathrm{bc}}$ \\
\hline
\end{tabular}

*Values were expressed as Means $\pm \mathrm{SE}$.

* Values at the same column with different letters are significant at $\mathrm{P}<0.05$.

The liver in turn, metabolizes thyroid hormones and regulates their systemic endocrine effects. Therefore, thyroid dysfunction may disturb liver function, and liver disease could affect thyroid hormone metabolism [82].

Also, Malik and Hodgson (2002) [83] has reported that liver injury caused by thyrotoxicosis is relatively common causing increased AST and ALT in about $27 \%-37 \%$ of thyrotoxic patients although the majority of them showed no clinical features of liver impairment. PTU-induced symptomatic hepatic injury is not rare and usually develops within the first few months of PTU administration [84]. Results illustrated in Table (4) showed that induction of hypothyroidism led to increased ALT and AST levels which could be attributed to the damage and necrosis of some liver cells and escape of their enzymes to the blood. Moreover, our results were compatible with Khan et al. (2010) [82] who reported that there is a positive relationship between thyroid hormones and liver enzymes where thyrotoxicosis is associated with a variety of liver dysfunction which could be attributed to mitochondrial dysfunction and hepatic tissues hypoxia.
Table 4. Effect of Iron, Zinc, Vitamin E and Vitamin C supplementation on liver functions in rats suffer from hypothyroidism.

\begin{tabular}{|c|c|c|c|}
\hline $\begin{array}{l}\text { Parameters } \\
\text { Groups }\end{array}$ & $\operatorname{ALT}(\mu / \mathbf{L})$ & $\operatorname{AST}(\mu / L)$ & $\operatorname{ALP}(\mu / L)$ \\
\hline Control - ve & $23.86 \pm 2.11^{\mathrm{c}}$ & $40.40 \pm 0.95^{\mathrm{e}}$ & $81.46 \pm 2.49^{d}$ \\
\hline Control + ve & $38.20 \pm 1.75^{\mathrm{a}}$ & $69.30 \pm 1.69^{\mathrm{a}}$ & $138.53 \pm 4.22^{\mathrm{a}}$ \\
\hline Iron & $32.26 \pm 1.78^{b}$ & $60.43 \pm 2.11^{\mathrm{b}}$ & $117.30 \pm 4.70^{b}$ \\
\hline Zinc & $30.36 \pm 0.93^{\mathrm{b}}$ & $58.76 \pm 3.69^{\mathrm{bc}}$ & $100.86 \pm 1.95^{\mathrm{c}}$ \\
\hline Vitamin E & $31.20 \pm 1.56^{\mathrm{b}}$ & $52.86 \pm 2.88^{\mathrm{cd}}$ & $111.26 \pm 4.39^{\mathrm{bc}}$ \\
\hline Vitamin C & $28.60 \pm 2.24^{\mathrm{bc}}$ & $50.23 \pm 1.64^{d}$ & $114.83 \pm 4.07^{\mathrm{b}}$ \\
\hline
\end{tabular}

*Values were expressed as Means $\pm \mathrm{SE}$.

* Values at the same column with different letters are significant at $\mathrm{P}<0.05$

The current results revealed that, feeding rats suffer from hypothyroidism with Iron, Zinc, Vit.E or Vit.C led to significant $(\mathrm{P}<0.05)$ decrease in the level of AST, ALT and ALP, compared with the positive control group. In regarding to ALT, there was no significant difference observed among the treated groups. Vitamin C supplementation was also able to cause reduction in ALT level to similar levels compared to 
normal group. On the other hand, the lowest decrease of the level of AST was seen in the groups fed on diet supplemented with Vit.C or Vit.E, then followed by the group fed on diet supplemented with either Zinc or Iron. It was seen that, there was no significant changes was seen in the level of ALP among the groups fed on diets supplemented with Iron, Vit.E or Vit.C. While, Zinc supplementation caused the lowest decrease in the level of ALP as compared to control positive group.

Zinc is a known fundamental component of the endogenous enzymatic antioxidant system with antioxidant properties playing an essential role in cell membrane integrity and functions in many aspects of cellular metabolism [85]. Thyroid gland hormones (T3 and T4) have an important role in maintaining the natural liver function [86]. Reiter et al. (2003) [87] has reported that antioxidant substances can prevent liver damage induced by thyroid dysfunction via increasing rate of elimination of free radicals and directly increasing the antioxidant activity. Zinc is not only required for cell-mediated immunity, but also an effective antioxidant and anti-inflammatory agent. Low serum and hepatic Zinc, and hyperzincuria were reported in patients with liver cirrhosis and Zinc therapy showed beneficial effects in subjects with hepatic steatosis, cirrhosis and encephalopathy [88]. Also, Murer et al. (2014) [89] has reported that Zinc as an antioxidant has a significant effect on ALT and AST levels. Zinc is capable of protecting against hepatotoxicity produced by a variety of chemicals [90]. Secondary and subclinical hypothyroidism were found in Iron deficiency anemia. Hormonal changes returned to normal values with Iron supplementation [55].

Vitamin $\mathrm{C}$ has been reported by researchers to have heptoprotective propertydue to its antioxidant property [91, 92]. Vitamin $\mathrm{E}$ at a dose of $50 \mathrm{IU} / \mathrm{kg}$ body weight protects against heavy metals-induced liver injury and the attenuating effect of Vit.E may be due to its antioxidant activity [93]. Administration of Vit.E at (10 IU/kg body weight/day), for 10 more weeks seems to exert a hypolipidemic and hepatoprotective role in the presence of a high-saturatedfat/high-cholesterol atherogenic diet in a rat model [94].

Data presented in Table (5) shows the effect of Iron, Zinc, Vit.E and Vit.C supplementation on kidney function in rats suffer from hypothyroidism. Results revealed that the rats suffer from hypothyroidism (control positive group) had significant $(\mathrm{P}<0.05)$ higher levels of urea and creatinine, compared with negative control group. PTU $(10 \mathrm{mg} / \mathrm{kg}$, IP for 18 day) administration to rats caused hyperemia and interstitial nephritis [95] with acute renal failure [96, 97]. Primary hypothyroidism is associated with a reversible elevation of serum creatinine in both adults [98] and children [99]. T4 and T3 are involved in kidney function in health and diseases condition, so the pathophysiology of kidney can be directly influenced and regulated by thyroid hormones. Hypothyroidism adversely affect the renal functions, development and in-return leading to reduced weight, kidney vascular disorders, electrolyte and lower filtration rate [100].

The current results illustrated that all hypothyroidism groups fed on diets supplemented with either Vit.E, Vit.C, Zinc or Iron had a significant $(\mathrm{P}<0.05)$ decrease in the level of urea and creatinine, compared with control positive group. Moreover, there was no significant differences were observed in the level of urea and creatinine among the treated groups. Results also revealed that the greatest decrease in serum urea and creatinine level was achieved in case of Vit.C supplementation, it was able to cause a reduction in creatinine level to similar levels of normal group. It was observed that, most of the renal manifestations of thyroid disorders, which are clinically most significant with hypothyroidism, are reversible with treatment.

Both human Idogun and Ajala (2005) [101] and animal Odigie et al. (2007) [102] studies have shown ascorbic acid to be a potent antioxidant which mediates its antioxidant effect by scavenging free reactive oxygen radicals before reaching to the renal. The nephroprotection of ascorbic acid (oral 100-500 mg/kg) in acetaminophen induced nephrotoxic rats which is characterized by marked elevation of serum urea and creatinine, could be due to its inherent antioxidant effect by inhibition of free radicals generation and/or free radical scavenging activity [103].

In addition, treatment with $\alpha$-tocopherol averted oxidative damage, probably through its capacity to quickly and efficiently scavenge lipid peroxide radicals before they attack the membrane lipids. Furthermore pre-treatment with Vit.E significantly increased the renal SOD activity [104, 17]. Pretreatment with Vit.E $(200 \mathrm{mg} / \mathrm{kg})$ significantly reduced the elevated serum creatinine and urea levels and improved kidney histopathological picture in rats with nephrotoxicity [105]. Similar results were found by Stojiljković et al. (2014) [106] who reported that gentamicin-induced nephrotoxicity can be significantly reduced by simultaneous administration of Vit.E (100 mg/kg).

Table 5. Effect of Iron, Zinc, and Vitamin E and C supplementation on kidney functions in rats suffer from hypothyroidism.

\begin{tabular}{|c|c|c|}
\hline \multirow{2}{*}{ Groups } & Urea & Creatinine \\
\hline & $(\mathrm{mg} / \mathrm{dl})$ & \\
\hline Control (-ve) & $32.80 \pm 1.33^{\mathrm{c}}$ & $0.64 \pm 0.073^{\mathrm{c}}$ \\
\hline Control (+ve) & $50.70 \pm 1.23^{\mathrm{a}}$ & $1.22 \pm 0.130^{\mathrm{a}}$ \\
\hline Iron & $43.20 \pm 3.41^{\mathrm{b}}$ & $0.99 \pm 0.011^{\mathrm{b}}$ \\
\hline Zinc & $40.93 \pm 2.55^{\mathrm{b}}$ & $0.93 \pm 0.038^{b}$ \\
\hline Vitamin E & $42.96 \pm 1.99^{b}$ & $0.95 \pm 0.047^{b}$ \\
\hline Vitamin C & $39.86 \pm 2.16^{b}$ & $0.82 \pm 0.076^{b c}$ \\
\hline
\end{tabular}

*Values were expressed as Means $\pm \mathrm{SE}$.

* Values at the same column with different letters are significant at $\mathrm{P}<0.05$

Furthermore, zinc chloride (4 mg/kg) had significantly decreased blood urea nitrogen and creatinine levels and protected kidney cells against cadmium induced toxicity [107].

Finally, It could be concluded that, there is some evidence to suggest that the administration of Vitamins ( $\mathrm{C}$ or $\mathrm{E})$ and Minerals (Zinc or Iron) in patients with hypothyroidism can decrease the severity of clinical symptoms and improve liver and kidney functions as well as lipid profile partly due to its antioxidant properties. 


\section{References}

[1] Laurberg, P., Andersen, S., Bulow, P., Carle, A. (2005). Hypothyroidism in the elderly: pathophysiology, diagnosis and treatment. Drugs Aging., 22: 23-38.

[2] Wiener, C. M. (2008). Harrison's Principles of Internal Medicine Self-Assessment and Board Review. 17th ed.; McGraw-Hill, Medical: New York, NY, USA, p. 1166.

[3] Berne, R. M. and Koeppen, B. M. (2010). Berne \& Levy Physiology, 6th ed.; Mosby/Elsevier: Philadelphia, PA, USA, pp. 721-723.

[4] Diekman, M. J.; Anghelescu, N.; Endert, E.; Bakker, O. and Wiersinga, W. M. (2000): Changes in plasma low-density lipoprotein (LDL)- and high-density lipoprotein cholesterol in hypo- and hyperthyroid patients are related to changes in free thyroxine, not to polymorphisms in LDL receptor or cholesterol ester transfer protein genes. J Clin Endocrinol Metab., 85: 1857-1862.

[5] Saleh, A. (2015). Lipid profile and levels of homocysteine and total antioxidant capacity in plasma of rats with experimental thyroid disorders. The Journal of Basic \& Applied Zoology, 72: $173-178$.

[6] Werner, S. C.; Ingbar, S. H.; Braverman, L. E. and Utiger, R. D. (2005).Werner \&Ingbar's the Thyroid: A Fundamental and Clinical Text, 9th ed.; Lippincott Williams \& Wilkins: Philadelphia, PA, USA,; p. 1166.

[7] Klein, I. and Danzi, S. (2007).Thyroid disease and the heart. Circulation; 116: 1725-1735.

[8] Mano, T.; Sinohara, R. and Sawai, Y. (1995). Effects of thyroid hormone on coenzyme $\mathrm{Q}$ and other free radical scavengers in rat heart muscle. J Endocrinol; 145: 131-136.

[9] Guerrero, A.; Pamplona, R.; Portero-Otin, M.; Barja, G. and Lopez-Torres, M. (1999). Effect of thyroid status on lipid composition and peroxidation in the mouse liver. Free Rad Biol Med; 26: 73-80

[10] Sarandol, E.; Tas, S.; Dirican, M. and Serdar, Z. (2005). Oxidative stress and serum paraoxonase activity in experimental hypothyroidism: effect of Vitamin $\mathrm{E}$ supplementation. Cell BiochemFunct; 23: 1-8.

[11] Erdamar, H.; Demirci, H.; Yaman, H.; Erbil, M. K.; Yakar, T.; Sancak, B.; Elbeg, S.; Biberoglu, G. and Yetkin, I. (2008). The effect of hypothyroidism, hyperthyroidism, and their treatment on parameters of oxidative stress and antioxidant status.ClinChem Lab Med; 46: 1004-1010.

[12] Evans, P. and Halliwell, B. (2001). Micronutrients: oxidant/antioxidant status. Br. J. Nutr.; 85: S67-S74.

[13] Halliwell, B. (2006). Oxidative stress and neurodegeneration: where are we now? Journal of Neurochemistry; 97(6):1634 1658.

[14] Messarah, M.; Boulakoud, M.; Boumendjel, A.; Abdennour, C. and El Feki, A. (2007). The impact of thyroid activity variations on some oxidizing-stress parameters in rats. C. R. Biologies; 330: 107-112.

[15] Peepre, K.; Bhimte, B.; Deshpandey, U. and Choudhary, P. (2014). Antioxidants Protect Cell Damage from Free Radicals:
A research study on Thyroid Hormones in Wistar Rats. Journal of Dental and Medical Sciences; 13, (1): 75-79.

[16] Subudhi, U.; Das, K.; Paital, B.; Bhanja, S. and Chainy, G. (2008). Alleviation of enhanced oxidative stress and oxygen consumption of L-thyroxine induced hyperthyroid rat liver mitochondria by Vitamin $\mathrm{E}$ and curcumin. ChemicoBiological Interactions; 173: 105-114.

[17] Ben Amara, I.; Karray, A.; Hakim, A. and et al., (2013). Dimethoate induces kidney dysfunction, disrupts membranebound ATPases and confers cytotoxicity through DNA damage. Protective effects of Vitamin E and selenium. Biol Trace Elem Res; 156: 230-242.

[18] Deshpande, U. R.; Joseph, L. J.; Patwardhan, U. N. and Samuel, A. M. (2002). Effect of antioxidants (Vitamin C, E and turmeric extract) on methimazole induced hypothyroidism in rats. Indian Journal Experimental Biology; 40, 735-738.

[19] Aihara, K.; Nishi, Y.; Hatano, S.; Kihara, M.; Yoshimitsu, K.; Takeichi, N.; Ito, T.; Ezaki, H. and Usui, T. (1984). Zinc, copper, manganese, and selenium metabolism in thyroid disease. Am. J. Clin. Nutr. 40: 26-35.

[20] Zimmermann, M. and Köhrle, J. (2004).The Impact of Iron and Selenium Deficiencies on Iodine and Thyroid Metabolism: Biochemistry and Relevance to Public Health., Thyroid., 12(10): 867-878.

[21] Formigari, A.; Irato, P. and Santon. A. (2007). Zinc, antioxidant systems and metallothionein in metal mediatedapoptosis: biochemical and cytochemical aspects. Comp Biochem Physiol C Toxicol Pharmacol., 146: 443-459.

[22] Catania, A. S.; Barros C. R. and Ferreira. S. R. (2009). Vitamins and minerals with antioxidant properties and cardiometabolic risk: controversies and perspectives. Arq Bras Endocrinol Metabol., 53:550-559.

[23] Wada, L. and King, J. C. (1986). Effect of low Zinc intakes on basal metabolic rate, thyroid hormones and protein utilization in adult men. J Nutr; 116: 1045-53.

[24] Nishiyama, S.; Futagoishi-Suginohara, Y.; Matsukura, M.; Nakamura, T.; Higashi, A.; Shinohara, M. and Matsuda, I. (1994). Zinc supplementation alters thyroid hormone metabolism in disabled patients with Zinc deficiency. J Am Coll Nutr., 13: 62-67.

[25] Baltaci, A. K.; Mogulkoc, R.; Bediz, C. S.; Kutlu, S.; Sandal, S. and Dogru, O., (1999). The effects of hypothyroidism on plasma levels of Zinc in rats. J. Turkey Med., 6: 105-109.

[26] Baltaci, A. K. 1.; Mogulkoc, R. and Belviranli, M. (2013). Serum levels of calcium, selenium, magnesium, phosphorus, chromium, copper and Iron--their relation to Zinc in rats with induced hypothyroidism. Acta Clin Croat. Jun; 52(2): 151-6.

[27] Sener, G.; Kabasakal, L.; Atasoy, B. M.; Erzik, C.; VeliogluÖgünç, A.; Çetinel, S. Q.; Contuk, G.; Gedik, N. andYegen, B. C. (2006). Propylthiouracil-induced hypothyroidism protects ionizing radiation-induced multiple organ damage in rats. Journal of Endocrinology, 189: 257-269.

[28] Reeves, R. G.; Nielsen, F. H. and Fahey, G. C. (1993). AIN-93 Purified Diets for Laboratory Rodents. J. Nutr., 123(1): 19391951.

[29] Agharanya, J. C. (1990). Clinical usefulness of ELISA technique in the assessment of thyroid function. West Afr. J. Med., 9(4): 258-63. 
[30] Frank, J. E.; Faix, J. E.; Hermos, R. J.; Mullaney, D. M.; Rojan, D. A.; Mitchell, M. L. and Klein, R. Z. (1996). Thyroid function in very low birth weight infants: effects on neonatal hypothyroidism screening. J. Pediatr., 128(4): 548-54.

[31] Sachidhanandam, M.; Singh, S. N.; Salhan, A. K. and Ray, U. S. (2010). Evaluation of plasma hormone concentrations using Enzyme-Immunoassay/Enzyme linked Immunosorbent assay in healthy Indianmen: Effect of ethnicity. Indian J. Clin. Biochem., 25(2): 153-7.

[32] Beutler, E.; Duron, O. and Kelly, BM. (1963). Improved method for the determination of blood glutathione. Lab Clin Med., 61: 882-8.

[33] Richmond, N. (1973). Colorimetric determination of total cholesterol and high density lipoprotein cholesterol (HDL-c). Clin. Chem., 19: 1350-1356.

[34] Wahlefeld, A. W., (1974). Methods of Enzymatic Analysis, Academic Press, Chapter, 5: 1831-1835.

[35] Albers, N.; Benderson, V. and Warnick, G. (1983). Enzymatic determination of high density lipoprotein cholesterol. Selected Methods. Clin. Chem., 10: 91- 99.

[36] Friedwald, W. T.; Leve, R. I. and Fredrickson, D. S. (1972). Estimation of the concentration of low density lipoprtein separated by three different methods. Clin. Chem., 18: 499-502.

[37] Reitman, S. and Frankel, S. A. (1957). Colorimetric method for determination of serum glutamic oxaloacetic and glutamic pyruvic transaminases. Am J Clin Path., 28: 56-63.

[38] Belfield, A. and Goldberg. D. M. (1971). Revised assay for serum phenyl phosphatase activity using 4- amino-antipyrineenzyme., 12: 561-573.

[39] Tietz, N. W. (1999). Text book of clinical chemistry.; (3rd ed). C. A. Burtis, E. R. Ashwood, W. B. Saunders. P. 477-530 to $1241-1245$

[40] Wills, M. R. and Savory, J. (1981). Biochemistry of renal failure. Ann. Clin. Lab. Sci., 11: 292-299.

[41] SPSS (1986). Statistical package for social science, version 11. SPSS Inc., II. U. S. A.

[42] Kelly, G. S. (2000). Peripheral metabolism of thyroid hormones.A review. Alt Med Rev. 25(4): 306-33.

[43] Ökten, A.; Mungan, Z. and Onuk, M. D. (1996). A case of propylthiouracil induced hepatotoxicity and hemolytic anemia. Tur J Gastroenterol, 7: 82-85.

[44] Bianco, A. C.; Salvatore, D.; Gereben, B.; Berry, M. J. and Larsen, P. R. (2002). Endocr. Rev. 23: 38.

[45] Norris, D. O. (2007).Vertebrate endocrinology.4th ed. Elsevier Inc.

[46] Arthur, J. R. and Beckett, G. J., 1999. Thyroid function. Br. Med. Bull.55: 658-668.

[47] Kralik, A.; Eder, K. and Kirchgessner, M. (1996). Influence of Zinc and selenium deficiency on parameters relating to thyroid hormone metabolism. Horm. Metab. Res. 28: 223-226.

[48] Vrca, V. B.; Skrebb, F.; Cepelakc, I.; Romicd, Z. and Mayerd, L. (2004). Supplementation with antioxidants in the treatment of Grave's disease; the effect on glutathione peroxidase activity and concentration of selenium. Acta. Clin. Chim., 341: 55-63.

[49] Kandhro, G.; Kazi, T.; Afridi, H.; Kazi, N.; Baig, J.; Arain, M. and et al., (2009). Effect of Zinc supplementation on the Zinc level in serum and urine and their relation to thyroid hormone profile in male and female goitrous patients., Clinical Nutrition., 28 (2): 162-168.

[50] Moustafa, S. A., 2001. Effect of glutathione (GSH) depletion on the serum levels of triiodothyronine (T3), thyroxine (T4), and T3/T4 ratio in allyl alcohol-treated male rats and possible protection with Zinc. Int. J. Toxicol. 20: 15-20.

[51] Beard, J. L.; Tobin, B. W. and Smith, S. M. (1990). Effects of Iron repletion and correction of anemia on norepinephrine turnover and thyroid metabolism in Iron deficiency. Proc Soc Exp Biol Med., 193: 306-12.

[52] Beard, J. L.; Brigham, D. E.; Kelly, S. K. and Green, M. H. (1998). Plasma thyroid hormone kinetics are altered in Irondeficient rats. J Nutr., 128: 1401-1408.

[53] Hurrell, R. F. (1999). Bioavailability of iodine. Eur J Clin Nutr., 51: S9-12.

[54] Hess, S. Y.; Zimmermann, M. B.; Arnold, M.; Langhans, W. and Hurrell, R. F. (2002). Iron deficiency anemia reduces thyroid peroxidase activity in rats. J. Nutr., 132: 1951-1955.

[55] Gökdeniz, E.; Demir, C. and Dilek, İ. (2010). The effects of Iron deficiency anemia on the thyroid functions. Journal of Clinical and Experimental Investigations, 1(3): 156-160.

[56] Soliman, G.; Mahfouz, M. and Emara, I. (2010). Effect of Different Types of Oral Iron Therapy Used for the Treatment of Iron Deficiency Anemia and Their Effects on Some Hormones and Minerals in Anemic Rats. Journal of American Science, 6(6): 109-118.

[57] Ambali, F.; Orieji, C.; Abubakar, W.; Shittu, M. and Kawu, M. (2011). Ameliorative Effect of Vitamin C on Alterations in Thyroid Hormones Concentrations Induced by Subchronic Coadministration of Chlorpyrifos and Lead in Wistar Rats. Journal of Thyroid Research Volume, Article ID 214924 1-6.

[58] Peepre, K.; Deshpandey, U. and Choudhary, P. S. (2014). Role of Antioxidants on Thyroid Hormones in Wister Rats. International Journal of Science and Research., 3 (1): 34-38.

[59] Resch, U.; Helsel, G.; Tatzber, F. and Sinzinger, H. (2002). Antioxidant status in thyroid disfunction.ClinChem Lab Med; 40(11): 1132-1134.

[60] Yilmaz, S.; Ozan, S.; Benzer, F. and Canatan, H. (2003). Oxidative damage and antioxidant enzyme activities in experimental hypothyroidism. Cell Biochem Funct., 21(4): 325-30.

[61] Das, K. and Chainy, G. B. 920040. Thyroid hormone influences antioxidant defense system in adult rat brain. Neurochem Res., 29(9): 1755-1766.

[62] Sankar, P.; Telang, A. G. and Manimaran, A. (2012). Protective effect of curcumin on cypermethrin-induced oxidative stress in Wistar rats. Experimental and Toxicologic Pathology; 64: 487-493.

[63] Sun, Y.; Ma, A.; Li, Y.; Han, X.; Wang, Q. and Liang, H. (2012). Vitamin E supplementation protects erythrocyte membranes from oxidative stress in healthy Chinese middleaged and elderly people. Nutrition research., 32: 328-334. 
[64] Hall, E. D.; Vaishnav, R. A. and Mustafa, A. G. (2010). Antioxidant therapies for traumatic brain injury. Neurotherapeutics.; 7(1): 51-61.

[65] Sarandol, E.; Tas, S.; Dirican, M. and et al. (2005). Oxidative stress and serum paraoxonase activity in experimental hypothyroidism: effect of Vitamin E supplementation. Cell Biochem Funct., 23: 1-8.

[66] Erdamar, H.; Demirci, H.; Yaman, H.; Erbil, M. K.; Yakar, T.; Sancak, B.; Elbeg, S.; Biberoglu, G. and Yetkin, I. (2008). The effect of hypothyroidism, hyperthyroidism, and their treatment on parameters of oxidative stress and antioxidant status.ClinChem Lab Med., 46: 1004-1010.

[67] Adali, M.; Inal-Erden, M.; Akalin, A. and Efe, B. (1999). Effects of propylthiouracil, propranolol, and Vitamin E on lipid peroxidation and antioxidant status in hyperthyroid patients. Clin Biochem., 32: 363-7.

[68] Alturfan, A. A.; Zengin, E.; Dariyerli, N., and et al., (2007). Investigation of Zinc and Copper Levels in MethimazoleInduced Hypothyroidism: Relation with the OxidantAntioxidant Status. Folia Biologica (Praha) 53: 183-188.

[69] Muller, M. J. and Seilz, H. J. (1984). Thyroid hormone action on intermediatary metabolism, Klin Wochenschr, 62: 49.

[70] Walsh, J. P.; Bremner, A. P; Leedman, M. J.; Feddema, P. and Mic, V. (2005). Dysfunction and Serum Lipids: A Community-Based Study. Clinical Endocrinology., 63(6): 670-675.

[71] Asvold, B. O.; Vatten, L. J.; Nilsen, T .I. and Bjoro, T. 92007). The Association between TSH within the Reference Range and Serum Lipid Concentrations in a Population based Study. The HUNT Study," European Journal of Endocrinology., 156: 181-186.

[72] Saleh, A. A. (2015). Lipid profile and levels of homocysteine and total antioxidant capacity in plasma of rats with experimental thyroid disorders. The Journal of Basic \& Applied Zoology, 72: 173-178.

[73] Pucci, E.; Chiovato, L. and Pinchera, A. (2000). Thyroid and lipid metabolism. Int J Obesity RelMetab Dis., 24: S109-S112.

[74] Duntas, L. H. (2002). Thyroid disease and lipids. Thyroid, 12: 287-293.

[75] Payahoo, L.; Ostadrahim, A.; Mobasseri, M. and et al., (2013). Effects of Zinc Supplementation on the Anthropometric Measurements, Lipid Profiles and Fasting Blood Glucose in the Healthy Obese Adults., Adv Pharm Bull. 3(1): 161-165.

[76] Al-Sabaawy, O. (2012). The Relationship Between Serum Lipid Profile and Selected Trace Elements for Adult Men in Mosul City., Oman Med J. 27(4): 300-303.

[77] Hennig, B.; Toborek, M. and McClain, C. J. (2001). Highenergy diets, fatty acids and endothelial cell function: implication for atherosclerosis. J Am Coll Nutr., 20: 91-105.

[78] Gunasekara, P.; Hettiarachchi, M.; Liyanage, C. and Lekamwasam, S. (2011). Effects of Zinc and multimineral Vitamin supplementation on glycemic and lipid control in adult diabetes. Diabetes Metab Syndr Obes., 4: 53-60.

[79] Choi, J.; Kim, S. and Pai,S. (2001). Changes in Serum Lipid Concentrations during Iron Depletion and after Iron Supplementation., Ann Clin Lab Sci., 31(2): 151-156.
[80] Dirican, M. and Tas, S. (1999). Effects of Vitamin E and Vitamin C supplementation on plasma lipid peroxidation and on oxidation of apolipoprotein B-containing lipoproteins in experimental hyperthyroidism. J Med Invest., 46: 29-33.

[81] Ajayi, A. F. and Akhigbe, R. E. (2012). Implication of altered thyroid state on liver function. Thyroid Res. Pract., 9: 84-87.

[82] Khan, T. M.; Malik, S. and Diju, I. U. (2010). Correlation between plasma thyroid hormones and liver enzyme level in thyrotoxic cases and control in hazara division. J. Ayub Med. Coll. Abbottabad., 22: 176-179.

[83] Malik, R. and Hodgson, H. (2002). The relationship between the thyroid gland and the liver. Q. J. Med., 95: 559-569.

[84] Lian, X. L.; Bai, Y.; Dai, W. X.; Guo, Z. S.; Li, W. and Lu, L. (2004). Propylthiouracil-induced overt hepatic injury in patients with hyperthyroidism.Zhongguo Yi Xue Ke Xue Yuan Xue Bao., 26(2): 172-7.

[85] Catania, A. S.; Barros, C. R. and Ferreira, S. R. (2009). Vitamins and minerals with antioxidant properties and cardio metabolic risk: controversies and perspectives. Endocrinol. Metabol., 53: 550-559.

[86] Malik, R.; Mellor, N.; Selden, C. and Hodgson, H. (2000). Characterizing the effects of thyroid hormone on the liver. Gut., 34 (1): 77-78.

[87] Reiter, R. J.; Tan, D. X.; Mayo, J. C.; Sainz, R. M. and Leon, J. (2003). Melatonin as an antioxidant: biochemical mechanisms and pathophysiological implications in humans. ActaBiochim. Pol., 50: 1129-1146.

[88] Prasad, A. S. (2013). Discovery of human Zinc deficiency: Its impact on human health and disease. Adv. Nutr., 4: 176-190.

[89] Murer, S. B.; Aeberli, I.; Braegger, C. P.; Gittermann, M.; Hersberger, M.; Leonard, S. W.; Taylor, A. W.; Traber, M. G. and Zimmermann, M. B. (2014). Antioxidant supplements reduced oxidative stress and stabilized liver function tests but did not reduce inflammation in a randomized controlled trial in obese children and adolescents. J. Nutr., 144 (2): 193-201.

[90] Ishikawa, T. (2012). Can Zinc enhance the response to interferon therapy in patients with HCV? World J. Gastroenterol., 18 (25): 3196-3200.

[91] Burtis, C. A. and Ashwood, E. R. (1994). Tietz Textbook of Clinical Chemistry, 2nd Edition, WB Saunders Co., Philedelphia, pp. 1275-1512.

[92] Netke, S. P.; Roomi, M. V.; Tsao, C. and Niedzwiecki, A., (1997).Ascorbic Acid Protects Guinea Pigs from Acute Aflatoxin Toxicity, Toxicology and Applied Pharmacology, 143, (2): $429-435$.

[93] Al-Attar, A. (2011). Vitamin E attenuates liver injury induced by exposure to lead, mercury, cadmium and copper in albino mice. Saudi Journal of Biological Sciences, 18(4): 395-401.

[94] Tzanetakou, I.; Doulamis, I.; Korou, L.; Agrogiannis, G. and et al., (2012). Water Soluble Vitamin E Administration in Wistar Rats with Nonalcoholic Fatty Liver Disease., The Open Cardiovascular Medicine Journal., 6: 88-97.

[95] Sepehri, G.; Derakhshanfar, A. and Saburi, L. (2013). Does Propylthiouracil Increase the Gentamicin-Induced Nephrotoxicity In Rat? Iran J Basic Med Sci. Nov., 16(11): $1190-1195$. 
[96] Fang, J. T. and Huang, C. C. (1998). Propylthiouracil-induced acute interstitial nephritis with acute renal failure requiring haemodialysis: successful therapy with steroids. Nephrol Dial Transplant., 13: 757-758.

[97] Nakahama, H.; Nakamura, H.; Kitada, O. and Sugita M. (1999). Chronic drug-induced tubulointerstitial nephritis with renal failure associated with propylthiouracil therapy. Nephrol Dial Transplant., 14: 1263-1265.

[98] Karanikas, G.; Schu“tz, M.; Szabo, M.; Becherer, A.; Wiesner, K.; Dudczak, R. and Kletter, K. (2004). Isotopic renal function studies in severe hypothyroidism and after thyroid hormone replacement therapy. American Journal of Nephrology., 24 $41-45$.

[99] Del-Rio, C. G.; Tapia, C. L.; and et al., (2003). Renal failure and acquired hypothyroidism. Pediatric Nephrology, 18: 290292.

[100] Mansourian, A. (2012). A literature review on the adverse effects of hypothyroidism on kidney function. Pakistan Journal of Biological Sciences, 15(15): 709-719.

[101] Idogun, E. S., and Ajala, M. O. (2005). Ascorbic Acid and Alpha Tocopherol Antioxidant Status of Type 2 Diabetes Mellitus Patients seen in Lagos. The Nigerian Postgraduate Medical Journal, 12 (3): 155-157.

[102] Odigie, I. P.; Okpoko, F. B. and Ojobor, P. D. (2007).
Antioxidant Effects of Vitamin C and E on PhenylhydrazineInduced Haemolysis in Sprague Dawley Rats: Evidence for A better Protection by Vitamin E. The Nigerian Postgraduate Medical Journal, 14(1): 1-7.

[103] Adeneye, A. A. and Olagunju, J. O (2009). Protective Effect of Oral Ascorbic Acid (Vitamin C) on AcetaminophenInduced Renal Injury in Rats"., African Journal of Biomedical Research, 12 (1): 55-61.

[104] Halliwell, B. and Gutteridge J. M. C. (2002) Free radicals in biology and medicine, vol. 3, Oxford University Press Inc., New York, pp. 105-245.

[105] Mehany, H.; Abo-youssef, A.; Ahmed, L.; Arafa, E. and Abd El-Latif, H. (2013). Protective effect of Vitamin E and atorvastatin against potassium dichromate-induced nephrotoxicity in rats, Journal of Basic and Applied Sciences, 2(2): 96-102.

[106] Stojiljković, N.; Ilić, S.; Veljković, M. and Todorović, J. (2014). Effects of supplementation with Vitamin e on gentamycin-induced acute renal failure in rats. Medicine and Biology, 16(2): 61-66.

[107] Morshedi, R.; Ahmadizadeh, M. and Angali, K. (2014). Protective Effects of Zinc Supplementation on Renal Toxicity in Rats Exposed to Cadmium, Jundishapur J Health Sci., 6(3): e21717. 